\title{
What're the risk factors for burned children in China? A review
}

\author{
Chan Nie \\ Department of Epidemiology and Health Statistics, \\ School of Public Health, Zunyi Medical University, \\ Zunyi, Guizhou, China \\ Tao Wang \\ Department of Epidemiology and Health Statistics, \\ School of Public Health, Zunyi Medical University, \\ Zunyi, Guizhou, China

\section{Huiting Yu} \\ Department of Epidemiology and Health Statistics, \\ School of Public Health, Zunyi Medical University, \\ Zunyi, Guizhou, China
}

\section{Xue Wang}

Department of Epidemiology and Health Statistics, School of Public Health, Zunyi Medical University, Zunyi, Guizhou, China

\section{Xiuquan Shi (Corresponding Author)}

Department of Epidemiology and Health Statistics, School of Public Health, Zunyi Medical University, Zunyi, Guizhou, China

Center for Injury Research and Policy \& Center for Pediatric Trauma Research, The Research Institute at Nationwide Children's Hospital, The Ohio State University College of Medicine, Columbus, OH, USA.

\section{ABSTRACT}

Objective: Childhood burns are a global public health problem, especially in low- and middle-income countries. This study conducted a review of children burns in order to better illustrate the risk factors of childhood burns in China. Methods: Through English and Chinese literatures, the prevalence of children burns was described, and the risk factors including age, gender, etiology of burn, season, location and the education level of guardians, lifestyle and customs were analyzed. Results: There is an estimate of 180,000 people dies from burns annually. Children under 3 years of age are the main age group of burns, and boys have a higher incidence of burns than girls. Hot fluids are the major cause of burns, and it is demonstrated that the causes of childhood burns have regional characteristics. The season that burn occurred varies from place to place. The most frequent place that burns occurred is in kitchens and bathrooms. In addition, parental education plays an important role on the prevention of child burns. Conclusion: Childhood burns can be prevented through enhancing publicity and education on burn prevention knowledge. Targeted measures should be taken to reduce the exposure of burn risk factors.

Keywords: Burn, Children, Risk factor, Etiology of burn 
Injury has been the main cause of disability and mortality among children in most of country. Among all the types of injury, burn ranked third next to traffic accidents and falls. Burns can result in the formation of scars of keloids that are bad looking; severe burns can even lead to joint contracture, joint deformity and difficulty in movement, causing a heavy psychological burden to patients, and a huge financial burden to their families and the society [1].

According to the report of World Health Organization (WHO), an estimate of 180,000 people dies from burns annually. Most of these occur in low- and middle-income countries, and almost two-thirds occur in the African and South-East Asian regions. At present, China's burn research on children mainly comes from two aspects: On is the injury monitoring system established by the National Center for Disease Control and Prevention; the other is the original research or case reports from burn medical workers in the hospital. China has a vast territory, that there are differences in geographic climate, economic conditions, cultural customs and living habits between the South and the North, the East and the West. This study made a review of child burns in order to better illustrate the risk factors of childhood burns in China.

\section{THE PREVALENCE OF CHILD BURNS}

Child burns are a global public health problem, especially in low- and middle-income countries where over $90 \%$ of children die from burn-related events [2]. In economically underdeveloped Africa, the infant burn rate is three times the world average [3]. In the European Union, burns have become the fourth leading cause of injury death to children, and the mortality rate of children under five is the highest [4]. According to Nasih Othman [5], the incidence of burns ranges from $112 / 100,000$ to $518 / 100,000$, and burns are one of the main causes of injury and mortality in all types. In China, about 10,000 people die of burns each year [6]. A survey of Jiangxi Province showed that the incidence of burns in children in this area was $0.034 \%$, and the contraction of burn scars resulted in impaired limb function and disability in children [7]. A prospective study of burns in Southwestern Hospital showed that the hospital had a burn rate of $1.8 \%$ [8]. Burns are a serious hazard. Severe burns can directly lead to death. Non-fatal burns can result in long-term hospitalization, disfigurement, and disability. Therefore, burns not only affect the patient's own physical and mental health, but also impose a heavy burden for the family and the country, causing the patient's family return to poverty.

\section{RISK FACTORS OF BURNS IN CHILDREN}

Age

A number of domestic studies have shown that children under 3 years of age are the main age group of burns [9-13], among which infants aged 1-3 years have the highest incidence. Most children under the age of 1 cannot walk autonomously. Their daily lives are guarded by their guardians. The scope of their activities is limited and the chance to contact with heat sources is very small. Therefore, the incidence of burns in children of this age is low. Otherwise, children age 1-3 years old had just learned to walk, their range of activity expanded, and they were eager to explore the unknown world. The chance of contact with heat, electricity and other hazards increased significantly, but they could not correctly judge and avoid risk factors in a timely manner, then the risk of burn increased. However, the majority of children aged 3-6 years have enrolled in kindergartens, chances to contact with heat sources in kindergartens decreased. With age increased, as well as the education of parents and teachers, they have a growing awareness of danger, thus the incidence of burns among children in this age group decreased. Children over the age of 7 have entered the school to study. School has relatively few heat sources; and their schoolwork pressure gradually increases and the playing time decreases; on the other hand, their knowledge has gradually accumulated that they can correctly identify risk factors; with the addition of physical flexibility increased, their ability to avoid risk factors increased. 


\section{Gender}

A large number of studies have shown that boys have a higher incidence of burns than girls [2, $10,12-15]$. It may because boys are lively, bold, and curious, who like to explore the unknown world and are more likely to access to burn risk factors than girls. Second, some parents are stricter with girls' behavior than boys. Otherwise, studies have also shown that the incidence of burn in girls is higher than that in boys [16], which may attribute to the differences of customs and social conditions.

\section{Etiology of burns}

Hot fluids are the major cause of burns [2, 17-19]. Common house burn hazards include hot porridge, hot soup, hot water bath, fire, even chemicals etc. With the development of economy, some families began to use water dispenser, and the children even like to play with the switch as a toy. The hot emitted water would burn the children's hands. Compared with foreign countries, Chinese people more like to drink boiled water, which is also an important risk of children burns. Flames in the family mainly come from cooking fires and heating in winter and spring, which risk is relatively small, since parents often monitor the fires when they are used. Children electric shocks are mostly caused by electric arc burns or accidental contact with electric wires under high-voltage lines. Now more and more families have electric bicycles. Some children will use electric bicycles as toys, and their hands may be burned by batteries. Therefore, children with electric injuries increased significantly in late childhood [20]. What's more, the improper storage of chemicals such as concentrated sulfuric acid, nitric acid, and pesticides can also harm to children.

\section{Season}

The season when burns happened varies from place to place, which may be the result of a combination of factors such as geographical environment, cultural customs and lifestyle habits. Domestic studies as Li's survey of Fuzhou [17] and Cai's survey of Shunde [21] showed the highest incidence in summer. The research of Zhou etc. showed that burn rate was highest in the winter and spring [14]. Yuan etc. showed that the incidence of burns was highest in spring and summer $[13,22]$.

\section{Location}

Children burns are commonly found in kitchens and bathrooms [23]. Cooking foods and cooking fires can cause burn to children, and having a bath can also cause burn. There is a study also pointed out that the living room and bedroom are the major sites of burns [24]. Most of the indoor burns caused by hot fluid, while most of outdoor burns caused by flame, like fireworks and firecrackers, burning wild grass, etc.

\section{The education level of guardians}

Studies have shown that parental education especially that of mother, has an impact on the occurrence of burns in children $[10,19,25,26]$. Children with maternal education of junior high school and below are more prone to burns. The education level of parents plays an important role in early childhood education. Parents with a low level of education have a poor knowledge of burn prevention and first aid. The higher education level, the stronger awareness of safety and prevention of burns, and a better understanding of first aid knowledge for burns the guardians have.

\section{Lifestyle and customs}

Different regions have different geographical environments, creating different living habits and cultural customs. Therefore, the causes of childhood burns have regional characteristics [27]. The etiologies of childhood burn in Sichuan area are dominated by boiling water, hot porridge, 
hot oil (hot oil) and other hot fluids, accounting for $94.41 \%$, which is closely related to Sichuan people's living habits [28]. People like to eat hot pot in Sichuan province, the hot pot soup is a mixture of oil and water, and children are easy to touch the end of the pot and get hurt when they are chasing. In northwestern region of China, there is a unique cause of burn- "Guo-LianKang", referring to the stove and the bed connected, accounted for $39.89 \%$ of the thermal fluid burns [29]. While a study of Switzerland [30] showed that burns have a higher prevalence on National day and Christmas day than other time, during which fireworks and candle lights are set to celebrate.

\section{CONCLUSION}

Child burns can be prevented. Primary prevention requires us to enhance publicity and education on burn prevention knowledge and carry out regular education activities in schools, communities, and villages. For specific causes of burns, targeted measures can be taken to reduce the exposure of risk factors. For example, a water dispenser switch with a child lock function can be designed to prevent children burned by hot water; optimizing the design of "Guo-Lian-Kang" to prevent children from falling into pots while playing. It is also important to promote the knowledge of first aid to implement effective treatment for secondary prevention. In the treatment of burns, it is not only to cure patients, but also to reduce the incidence of burn sequelae to ease the physical and psychological burden of patients. It is a positive and meaningful task for patients, families, and the entire society to adopt active and effective measures to reduce the incidence of child burns.

\section{DISCLOSURE}

The authors report no conflicts of interest in this work.

\section{ACKNOWLEDGMENTS}

This study was granted by National Natural Science Foundation of China (grant No. 81560534, PI: Xiuquan Shi).

\section{References}

Le Q, Chen Y, Wang X, Hong J, Sun X, Xu J. Analysis of medical expenditure and socio-economic status in patients with ocular chemical burns in East China: a retrospective study[J]. Bmc Public Health, 2012,12(1):409.

Wesson HK, Bachani AM, Mtambeka P, Schulman D, Mavengere C, Stevens KA, Millar AJ, Hyder AA, van As AB. Pediatric burn injuries in South Africa: a 15-year analysis of hospital data[J]. Injury-international Journal of the Care of the Injured, 2013,44(11):1477-1482.

Gevaart-Durkin A, Swart D, Chowdhury Z. A study of energy-related injuries from hospital admissions among children and adults in South Africa[J]. Burns Journal of the International Society for Burn Injuries, 2014,40(6):1209-1218.

MacKay M, Vincenten J. How safety conscious are European countries towards children[J]. Child Safety Report Card, 2012.

Othman N, Kendrick D. Epidemiology of burn injuries in the East Mediterranean Region: a systematic review[J]. Bmc Public Health, 2010,10(1):83.

SY W, YH L, GB C, SY X, J O-S, M S, MR P. Injury-related fatalities in China: an under-recognised public-health problem[J]. The Lancet, 2008,372(9651):1765- 1773.

Zhao Jun, Li Ai, Zhu Li-Ping, et al. Analysis of burn and scald among children in jiangxi province[J]. Modern Preventive Medicine, 2009,36(8):1401-1403. (In chinese)

Huang Y, Zhang L, Lian G, Zhan R, Xu R, Huang Y, Mitra B, Wu J, Luo G. A novel mathematical model to predict prognosis of burnt patients based on logistic regression and support vector machine[J]. Burns Journal of the International Society for Burn Injuries, 2016,42(2):291-299.

Lei Lin, Huang Zhihui, Zhou Haibin, Peng Ji. Epidemiological characteristics of injured children aged 0-14 years in Shenzhen, 2015- 2016 [J] China Tropical Medicine, 2017,17(11):1115-1117. (In chinese) 
Mo Qingyi, Huang Dongming, Xie Guangqing, Liang Guiming, Ma Lizhong, Fu Simao. Unintentional injuries in children: an analysis of 924 cases [J]. Chin J Contemp Pediatr, 2013,15(7):559-562. (In chinese)

Lin Guoan, Yang Xiaodong, Lin Zhichen, et al. Epidemiological feature analysis of hospitalized pediatric burns in South Henan during 1962-2012yr. [J]. Prac J Med \& Pharm,2017,34(7):592-594.(In chinese)

Zhu L, Zhang Y, Liu L, Jiang J, Liu Y, Shi F, Yi D. Hospitalized pediatric burns in North China: a 10-year epidemiologic review[J]. Burns, 2013,39(5):1004-1011.

Xu JH, Qiu J, Zhou JH, Zhang L, Yuan DF, Dai W, Gao ZM. Pediatric burns in military hospitals of China from 2001 to 2007: a retrospective study[J]. Burns, 2014,40(8):1780-1788.

Bo Z, Xiao Z, Li-Zhi O, Xiao-Yuan H, Pi-Hong Z, Ming-Hua Z, Li-Cheng R, Peng-Fei L. An epidemiological analysis of paediatric burns in urban and rural areas in south central China[J]. Burns Journal of the International Society for Burn Injuries, 2014,40(1):150-156.

Santos JV, Oliveira A, Costa-Pereira A, Amarante J, Freitas A. Burden of burns in Portugal, 2000-2013: A clinical and economic analysis of 26,447 hospitalisations[J]. Burns, 2016,42(4):891-900.

Eser T, Kavalci C, Aydogan C, Kayipmaz AE. Epidemiological and cost analysis of burn injuries admitted to the emergency department of a tertiary burn center[J]. Springerplus, 2016,5(1):1411.

Li Lin, Lin Renqin, Xu Le, Pan Qiong, Dai Jiaxi, Jiang Meiyun, Chen Zhaohong. Epidemiological investigation of hospitalized children with burn injuries in a hospital of Fuzhou [J]. Chin J Burns, 2016,32(6):351-355. (In chinese)

Li Yong, Xu Jin, Zhang Xiangzhou, Wu Zhuming, Yu Yong. Epidemiological characteristics of 1552 pediatric burns [J]. Chin J Injury Repair and Wound Healing (Electronic Edition), 2014(5):506-511. (In chinese)

Shi S, Yang H, Hui Y, Zhou X, Wang T, Luo Y, Xiang H, Shi X. Epidemiologic characteristics, knowledge and risk factors of unintentional burns in rural children in Zunyi, Southwest China[J]. Scientific reports, 2016,6:35445.

Karimi H, Montevalian A, Motabar AR, Safari R, Parvas MS, Vasigh M. Epidemiology of paediatric burns in Iran[J]. Annals of Burns \& Fire Disasters, 2012,25(3):115-120.

Cai Xiaoyan, Lin Lianduo, Feng Yudong, Zhou Naxi, Mai Qifeng, Long Zhaolin. Epidemiological characteristics of 1 671 cases of burned patients in Shunde, Guangdong Province[J]. Guangdong Medical Journal, 2014,35(13):21122114. (In chinese)

Yuan Bo, Miao MingYuan, Yang HuiZhong, Huan JingNing. Epidemiological study on hospitalized burns children admitted by Department of Burns and Plastic Surgery of Ruijin Hospital during 2003-2012 [J]. Journal of Shanghai Jiaotong University(Medical Science), 2015,35(4):535. (In chinese)

Koç Z, Sağlam Z. Burn epidemiology and cost of medication in paediatric burn patients[J]. Burns, 2012,38(6):813819.

Liang Feng. The study of the epidemiological features and influential factors for children burns in several hospitals of Beijing[D]. Hebei Medical University, 2009. (In chinese)

Alnababtah K, Khan S, Ashford R. Socio-demographic factors and the prevalence of burns in children: an overview of the literature[J]. Paediatrics \& International Child Health, 2016,36(1):45-51.

Liu Y, Cen Y, Chen JJ, Xu XW, Liu XX. Characteristics of paediatric burns in Sichuan province: epidemiology and prevention[J]. Burns, 2012,38(1):26-31.

Nie C, Wang T, Zeng X, Shi X. Poor Supervision Leading to Carbon Monoxide Intoxication in a Burned Child[J]. Journal of Case Reports,2017,7(3):293-295.

Li Chaoqun, Wang Xiaolei. Investigation and Analysis of 179 Hospitalized Children with Burns [J]. Chinese Pediatric Emergency Medicine, 2003,10(4):245.(In chinese)

Zhu L, Zhang H, Shi F, Yi D, Zhu G. Epidemiology and outcome analysis of scalds in children caused by "guo lian kang": An 11-year review in a burn center in China[J]. Burns, 2015,41(2):289-296.

Müller M, Moser EM, Pfortmueller CA, Olariu R, Lehmann B, Exadaktylos AK. Aetiology of adult burns treated from 2000 to 2012 in a Swiss University Hospital[J]. Burns, 2016,42(4):919-925. 